\title{
Organoleptic Analysis of Doughs Fermented with Yeasts From A Nigerian Palm Wine (Elaeis guineensis) and Certain Commercial Yeasts
}

\author{
Boboye, B.*, Dayo-Owoyemi, I. and Akinyosoye, F. A. \\ Department of Microbiology, Federal University of Technology, P. M. B. 704, Akure, Ondo State, Nigeria
}

\begin{abstract}
Yeasts isolated from a freshly tapped palm wine obtained from Akure, Nigeria were identified as Schizosaccharomyces pombe, Saccharomyces cerevisiae, Debaryomyces hansenii, Geotrichum lactis and Zygosaccharomyces rouxii. Each of the isolates was used to ferment wheat flour dough and baked. Sensory analysis of the doughs was carried out on leavening, texture, aroma, taste and appearance. Saccharomyces cerevisiae performed best in leavening the dough while Debaryomyces hansenii produced doughs with the best taste and aroma. Appearances of the doughs made with all the isolated yeasts did not differ significantly $(\mathrm{P}<0.05)$ from that of the dough that lacked yeast.
\end{abstract}

Key Words: A Nigerian palm wine, Yeasts, Sensory properties of dough.

\section{INTRODUCTION}

Palm wine is an alcoholic beverage produced by the natural fermentation of the sap of various palm trees. Among the palms used are coconut (Cocus nucifera), oil palm (Elaeis guineensis), date palm (Phoenix clotifera) and raphia palm (Raphia hookeri) [1]. The unfermented sap is a clean, sweet, colourless syrup containing about $10-12 \%$ (w/v) sugar, which is mainly sucrose [2]. Upon fermentation by the natural microflora, the level of this sugar decreases as it converts to alcohol and other products whereas the sap becomes milky white due to the increased microbial suspension resulting from the prolific growth of fermenting organisms [3].

Previous study on the microbiology of Elaeis guineensis have incriminated several bacteria and yeast flora to be involved in the fermentation process [2]. Ezenroye and Okerentugba [4] reported the genetically and physiologically different isolated yeasts from palm wine. These variants include nine species of Saccharomyces cerevisiae, three Candida species, one Schizosaccharomyces species and one Kluyveromyces species.

Literatures have shown that bakers have used palm wine as a cheap alternative dough-leavening agent. Palm wine is able to raise dough because it harbours many yeast species. However, fermented baked dough produced using palm wine as a substitute for baker's yeast is usually characterized by a sharp sour taste, pronounced palm wine flavour and short shelf life (Personal communication in 2007 with Kole, Kole bakery, Akure, Ondo State, Nigeria). This sour taste and short shelf life could be attributed to the large number of microbial flora, particularly the lactic acid bacteria present in palm wine [5] that produce metabolites undesirable for bread production.

*Address correspondence to this author at the Department of Microbiology, Federal University of Technology, P. M. B. 704, Akure, Ondo State,

Nigeria; E-mail: boboye_b@yahoo.com
Elaeis guineensis harbours many yeast species [2]. Although considerable amount of work has been done in characterizing the yeast strains present in palm wine, there are only few information available on the leavening ability of the yeasts. Also, the location or environment where the palm wine is can determine the exact type of yeasts present in the drink. Therefore, this work was designed to isolate and identify yeasts present in palm wine freshly tapped in Akure, Nigeria and determine the dough leavening ability of these yeasts. The organoleptic properties of the doughs made with these microbes were investigated.

\section{MATERIALS AND METHODOLOGY}

\section{Microbial Analysis}

A $1 \mathrm{~mL}$ aliquot of freshly tapped palm wine was aseptically collected from an Ijoka farm, Akure, Nigeria. The sample was serially diluted 100 folds after which $1 \mathrm{~mL}$ was pour-plated [6] in triplicate using PDA containing $0.1 \%$ $(\mathrm{w} / \mathrm{v})$ lactic acid. The plates were placed at $30^{\circ} \mathrm{C} \pm 2{ }^{\circ} \mathrm{C}$ for $48-72$ hours. After good growth of the colonies, distinct colonies were purified on fresh PDA by streaking. Each colony was confirmed to be yeast by examining it under a light microscope using oil immersion objective after staining with lactophenol-in-cotton-blue dye. Pure isolates were placed on PDA slants and stored at $4{ }^{\circ} \mathrm{C}$ until needed.

The yeasts isolate were characterized based on their cultural characteristics (colony shapes, pigment, elevation, edge and surface appearance). Biochemical characterization of the isolates was done by testing for ability of the yeasts to ferment and assimilate sugars, utilize nitrate, form pellicle, spore, pseudomycelium and mycelium according to the methods of Harrigan, Olutiola et al., Barnett et al. and Fawole \& Oso [6-9].

\section{Cultivation of Yeast Isolates for Dough Fermentation}

The yeasts isolated were cultured separately at $25^{\circ} \mathrm{C} \pm$ $2{ }^{\circ} \mathrm{C}$ in peptone broth medium containing $20 \%(\mathrm{w} / \mathrm{v})$ glucose and lactic acid at concentration of $0.2 \%$ in 1 litre conical 
flask equipped with air locks. The set-up was agitated continuously for 72 hours in rotary shaker regulated at $150 \mathrm{rpm}$. After good growth was observed, the biomass concentrate for each yeast species was obtained by centrifuging it in an MSE centrifuge machine at $12,168 \times 10^{3} \mathrm{~g}$ for $10 \mathrm{~min}$. The yeast concentrates were washed sufficiently with sterile distilled water after which they were resuspended in sterile distilled water. The same procedure was applied to the commercial yeasts (Saf-instant and STK Royal) used as controls.

\section{Determination of Fermentative Ability of the Yeasts}

All the yeast isolates were used to ferment dough in order to test their fermentative ability. Samples of dough were prepared as described by Cauvian and Young [10]. Each dough sample contained wheat, flour, salt, water, sugar and fat. All the ingredients were properly mixed. Each yeast isolate (1.41 $\mathrm{x} 10^{9} \mathrm{Cfu} / \mathrm{mL}$ ) was used to ferment the dough. Baker's yeast (STK Royal and Saf- instant) were used separately as positive control yeasts to ferment the dough. Another set of dough formulation that did not contain any yeast sample was prepared as the negative control. The dough samples were left to ferment at room temperature at $37^{\circ} \mathrm{C} \pm 2{ }^{\circ} \mathrm{C}$ for about 1 hour. The doughs were baked in an oven for $1 \mathrm{hr}$ at $200^{\circ} \mathrm{C}$.

\section{Comparative Analysis of the Baked Dough Samples}

The baked dough samples were subjected to sensory analyses by using panel of 26 enlightened judges to evaluate the following physical parameters namely: leavening, taste, texture, appearance and aroma. Five points grade was used in the analysis starting with Excellent $=5$, Very Good $=4$, Good $=3$, Satisfactory $=2$ and Poor $=1$.

\section{Analysis of Data}

All data obtained from sensory evaluation were subjected to statistical analysis by using Analysis of Variance and DUNCAN Multiple Range Test. Significance of variations in the analyzed data was tested at $95 \%$ confidence limit.

\section{RESULTS AND DISCUSSION}

Five morphologically different yeast strains namely Schizosaccharomyces pombe, Debaryomyces hansenii, Geotrichum lactis, Saccharomyces cerevisiae and Zygosaccharo-myces rouxii were obtained from the freshly tapped palm wine (Table 1). The quantity and complexity of yeasts isolated from the palm wine used in this study is in agreement with the findings of Ezenronye and Okerentugba [4].
The complexity and variation in species of yeasts isolated is related to the fact that the yeasts originate from several sources such as the tapping container (which may retain some yeasts) and from the tapping environment. Furthermore, palm wine contains a high level of sucrose (10-12\%). This high sugar level favours the growth of yeasts. It further gives credence to the general belief held in the early days of research that yeasts are found in sugary substances [11].

The organoleptic properties of doughs fermented with the various yeast isolates are presented in Figs. 1-5. The figures show that they compared well with doughs produced using commercial yeasts (Saf-instant and STK Royal) in all sensory attributes tested (leavening, texture, aroma, taste and appearance). All the isolates showed fermentative ability as depicted by their leavening activities (Fig. 1). Mean ratings of the leavening activities of the yeasts range between 2.33 (Zygosaccharomyces rouxii) and 2.83 (Saccharomyces cerevisiae). This corresponds to good leavening abilities on the sensory scale used at significant level of $\mathrm{P}<0.05$.

The analysis of variance (ANOVA) shows that one of the commercial yeasts (Saf-instant) did not differ significantly from Schizosaccharomyces cerevisiae and Debaryomyces hanseni $(\mathrm{P}<0.05)$ in its leavening performance. The commercial yeasts STK Royal and Saf-instant had mean leavening activities of 2.70 and 2.40 respectively while the negative control (dough which lacked yeast) scored 2.29.

When compared with the negative control, the data showed that the isolated yeasts increased the size of doughs which they fermented considerably. This confirms the basis of using palm wine as a substitute for baker's yeast by some bakers. The result is supported by the abilities of the yeasts to ferment sugars especially glucose and fructose, the break down of which brings about the release of carbon dioxide that causes dough to rise. The highest leavening activity recorded for $S$. cerevisiae indicates that it is the best biological wheat dough leavener obtained in this work because it performed better than the two commercial yeasts used as controls. The result is in agreement with the findings of Somiari and Udoh [12] and Adenaike et al. [13] who reported that Saccharomyces species isolated from palm wine were found to be the best in leavening wheat dough.

The mean texture ratings obtained for the doughs fermented with the yeast isolates range between 2.84 (S. cerevisiae) and 2.14 (Zygosaccharomyces rouxii) (Fig. 2). This score range falls within good on the sensory scale used. The texture score recorded for $S$. cerevisiae followed the same

Table 1. Morphological and Biochemical Characteristics of the Yeasts Isolated from Palm Wine in Akure, Nigeria

\begin{tabular}{|c|c|c|c|c|c|c|c|c|c|c|c|c|c|c|c|c|c|c|c|}
\hline \multirow{3}{*}{$\sum_{i}^{\dot{z}}$} & \multicolumn{7}{|c|}{ MORPHOLOGY } & \multicolumn{12}{|c|}{ BIOCHEMICAL PROPERTIES: FERMENTATION/ASSIMILATION } \\
\hline & \multirow[b]{2}{*}{ Cell Shape } & \multicolumn{2}{|c|}{ Ascospore } & \multirow{2}{*}{ के } & \multirow[b]{2}{*}{ Ps } & \multirow[b]{2}{*}{ My } & \multirow[b]{2}{*}{$\mathbf{P e}$} & \multirow[b]{2}{*}{ GI } & \multirow[b]{2}{*}{ Ga } & \multirow[b]{2}{*}{ Su } & \multirow[b]{2}{*}{ Fr } & \multirow[b]{2}{*}{$\mathbf{L a}$} & \multirow[b]{2}{*}{ Ma } & \multirow[b]{2}{*}{$\mathbf{R a}$} & \multirow[b]{2}{*}{$\mathrm{Ce}$} & \multirow[b]{2}{*}{$\mathbf{X y}$} & \multirow[b]{2}{*}{ Ar } & \multirow[b]{2}{*}{ Mn } & \multirow[b]{2}{*}{ Yeast Identity } \\
\hline & & Present/Absent & Shape & & & & & & & & & & & & & & & & \\
\hline A & Cylindrical & ND & ND & + & - & - & + & FA & $-\mathrm{A}$ & FA & FA & -- & $-\mathrm{A}$ & FA & $-\mathrm{A}$ & $-\mathrm{A}$ & -- & FA & Schizosaccharomyces pombe \\
\hline $\mathrm{B}$ & Oval & + & Oval & + & + & - & + & FA & FA & FA & FA & FA & $-\mathrm{A}$ & $-\mathrm{A}$ & $-\mathrm{A}$ & -- & -- & $-\mathrm{A}$ & Debaryomyces hansenii \\
\hline $\mathrm{C}$ & Oval & + & Oval & + & - & + & + & FA & FA & $-\mathrm{A}$ & FA & FA & $-\mathrm{A}$ & $-\mathrm{A}$ & $-\mathrm{A}$ & $-\mathrm{A}$ & $-\mathrm{A}$ & FA & Geotrichum lactis \\
\hline $\mathrm{D}$ & Oval & + & Oval & + & + & - & - & FA & FA & FA & FA & -- & FA & FA & -- & -- & -- & $-\mathrm{A}$ & Saccharomyces cerevisiae \\
\hline $\mathrm{E}$ & Spherical & + & Oval & + & + & - & - & FA & FA & $\mathrm{FA}$ & FA & -- & $-\mathrm{A}$ & FA & -- & -- & -- & FA & Zygosaccharomyces rouxii \\
\hline
\end{tabular}

Keys: Ps: Pseudomycelium, My: Mycelium, Pe: Pellicle, Gl: Glucose, Ga: Galactose, Su: Sucrose, Fr: Fructose, La: Lactose, Ma: Maltose, Ra: Raffinose, Ce: Cellobiose, Xy: Xylose, Ar: Arabinose, Mn: Mannose, +: Positive or Present, -: Negative or Absent, FA: Fermentation and Assimilation, -A: Assimilation only, ND: Not Determined 


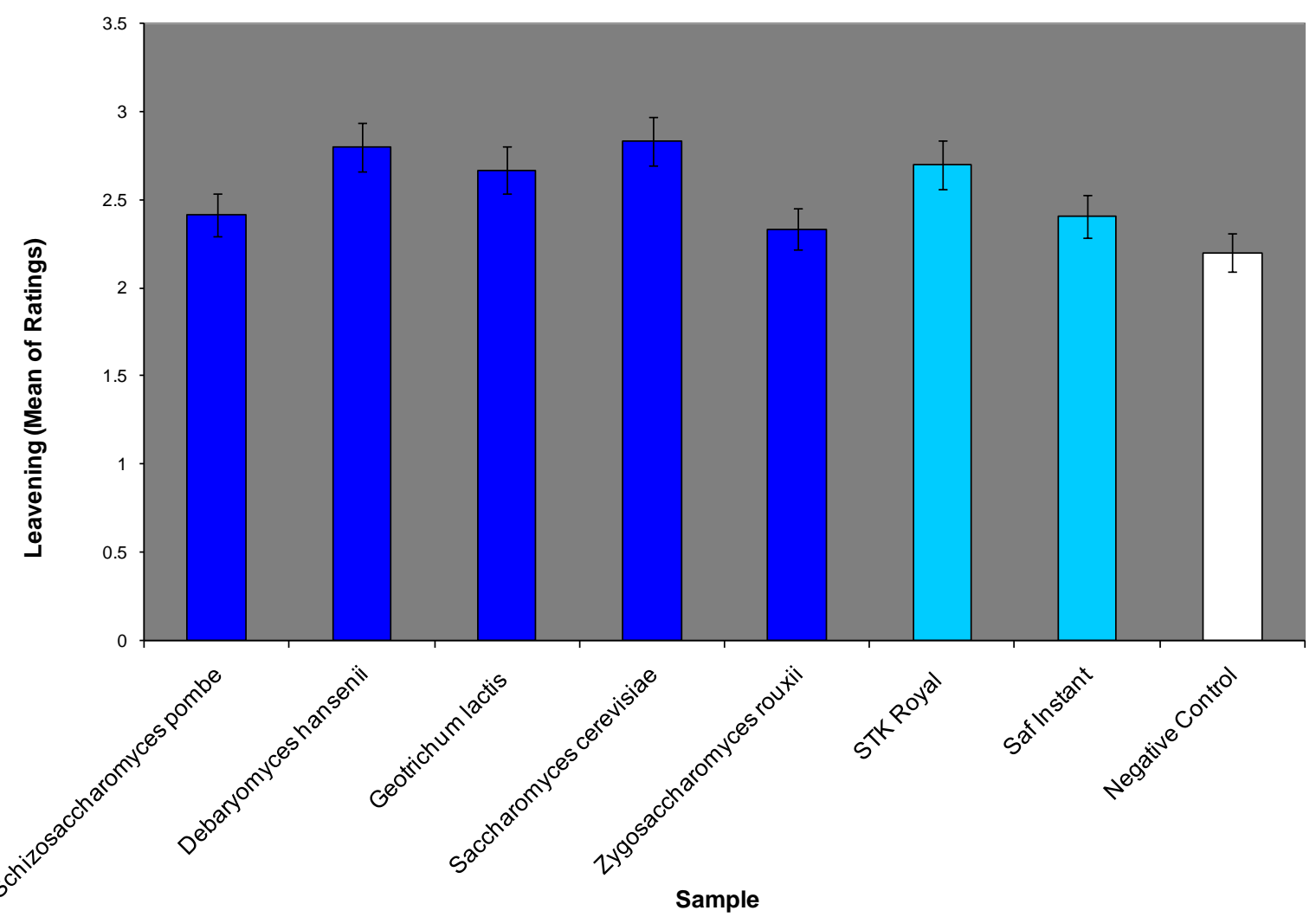

Fig. (1). Dough leavening activities of the various yeasts isolated from palm wine.

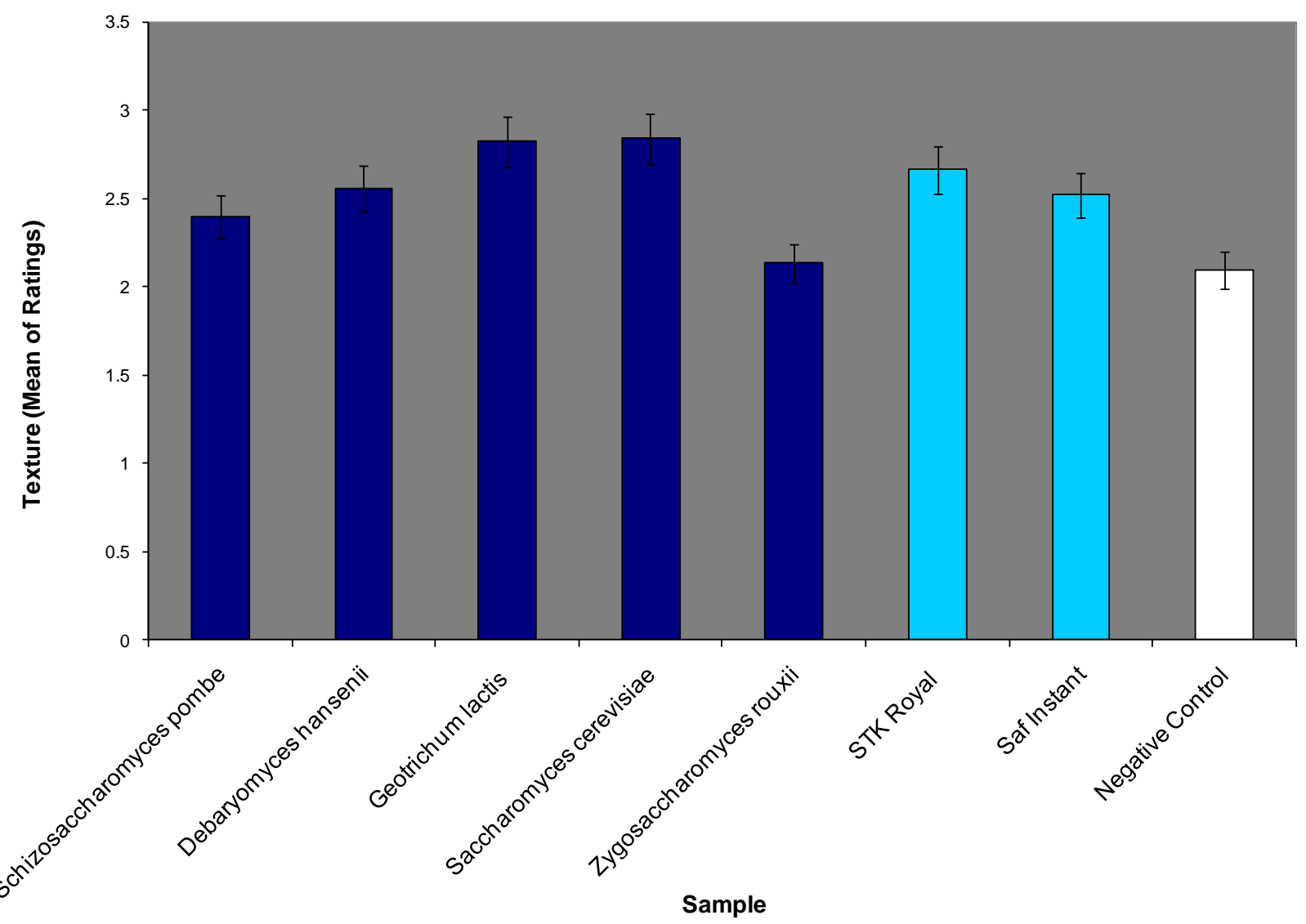

Fig. (2). Texture of baked doughs made with the various yeasts isolated from palm wine. 
trend as its leavening activity since the highest texture score was obtained for it. Olorunfemi and Adetuyi [14] reported a similar finding. Geotrichum lactis had the next high score for texture (2.82) followed by Debaryomyces hansenii and Schizosaccharomyces cerevisiae at 2.56 and 2.40 ratings respectively. Generally, the texture ratings of doughs fermented with these yeasts are at very close range to their leavening activity ratings, thus suggesting that besides causing dough to rise, the yeasts have improved the texture of the doughs they fermented. This confirmed the statement of Corriher [15] that expansion of dough due to the carbon dioxide produced by yeasts leads to a characteristic porosity and texture of fermented baked dough. The low leavening activity and texture ratings of the negative control (dough which lacked yeast) confirms the effect of yeast on the fermented baked doughs.
Doughs fermented with the yeasts showed varying acceptance levels of aroma (Fig. 3). Debaryomyces hansenii produced dough with the best aroma (3.16). This was followed by Saccharomyces cerevisiae, Schizosaccharomyces pombe, Zygosaccharomyces rouxii and Geotrichum lactis with aroma ratings of 2.91, 2.80, 2.67 and 2.65 respectively. All the yeasts produced doughs with aroma ratings comparable with those of the commercial yeasts. The good and very good ratings of aroma indicate that the yeasts were able to produce compounds such as carbonyls, aldehydes and ketones that have imparted appealing flavours into the doughs.

The mean taste and appearance scores obtained for the dough fermented with the isolated yeasts and those of the commercial yeasts as well as the dough which lacked yeast range between 2.87 and 3.32 for taste and 2.76 and 3.17 for appearance (Figs. 4 and 5). The taste and appearance of the

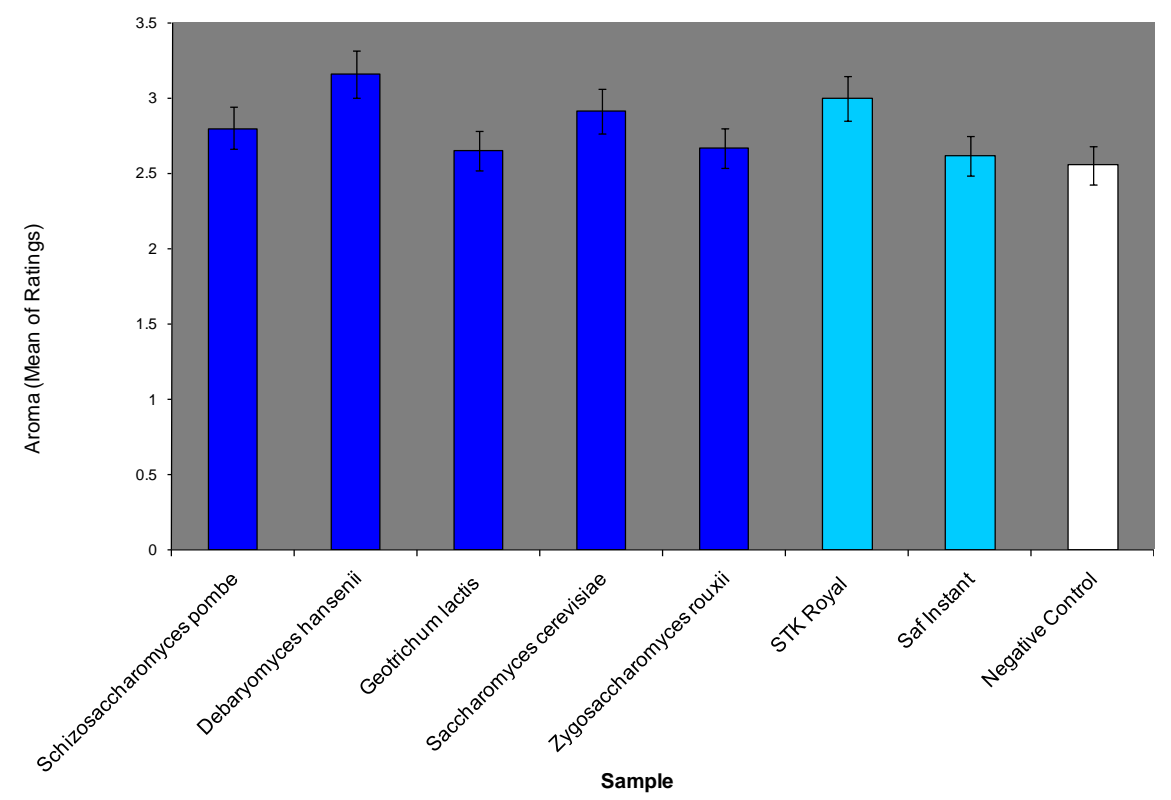

Fig. (3). Aroma of baked doughs made with the various yeasts isolated from palm wine.

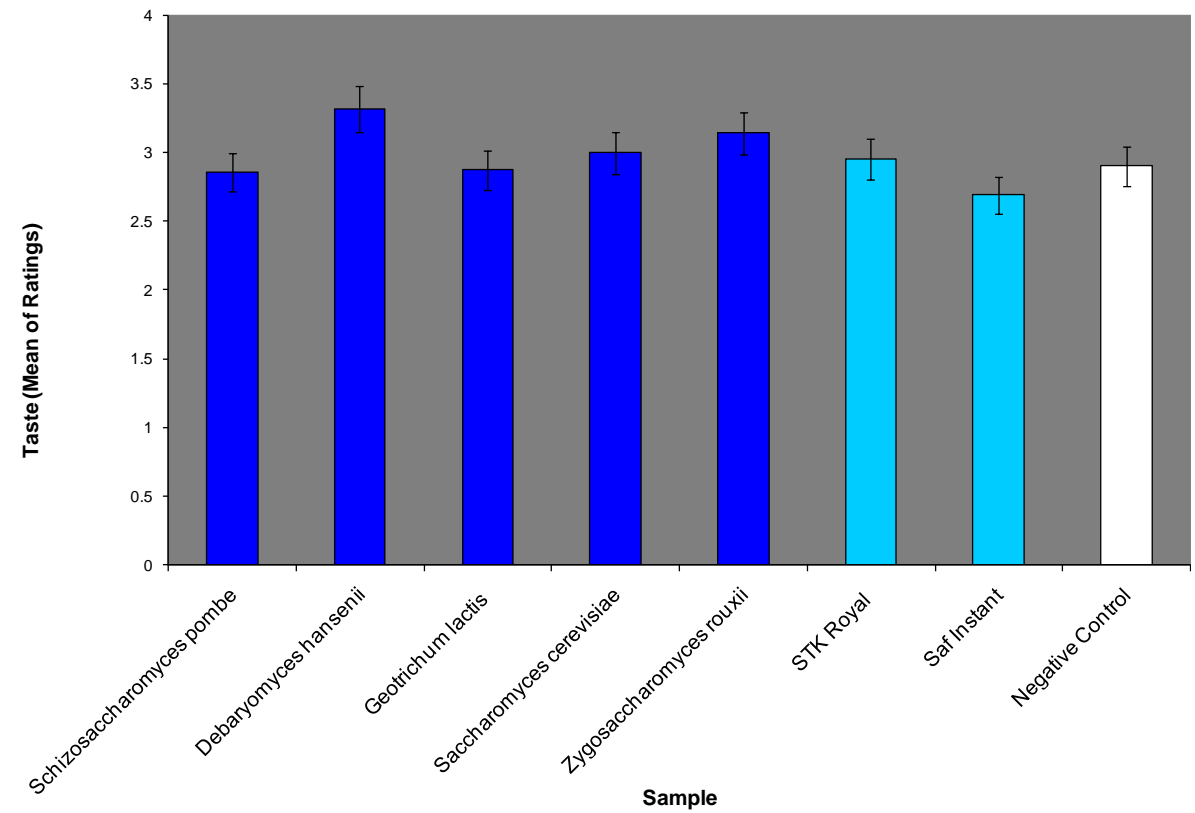

Fig. (4). Taste of baked doughs made with the various yeasts isolated from palm wine. 


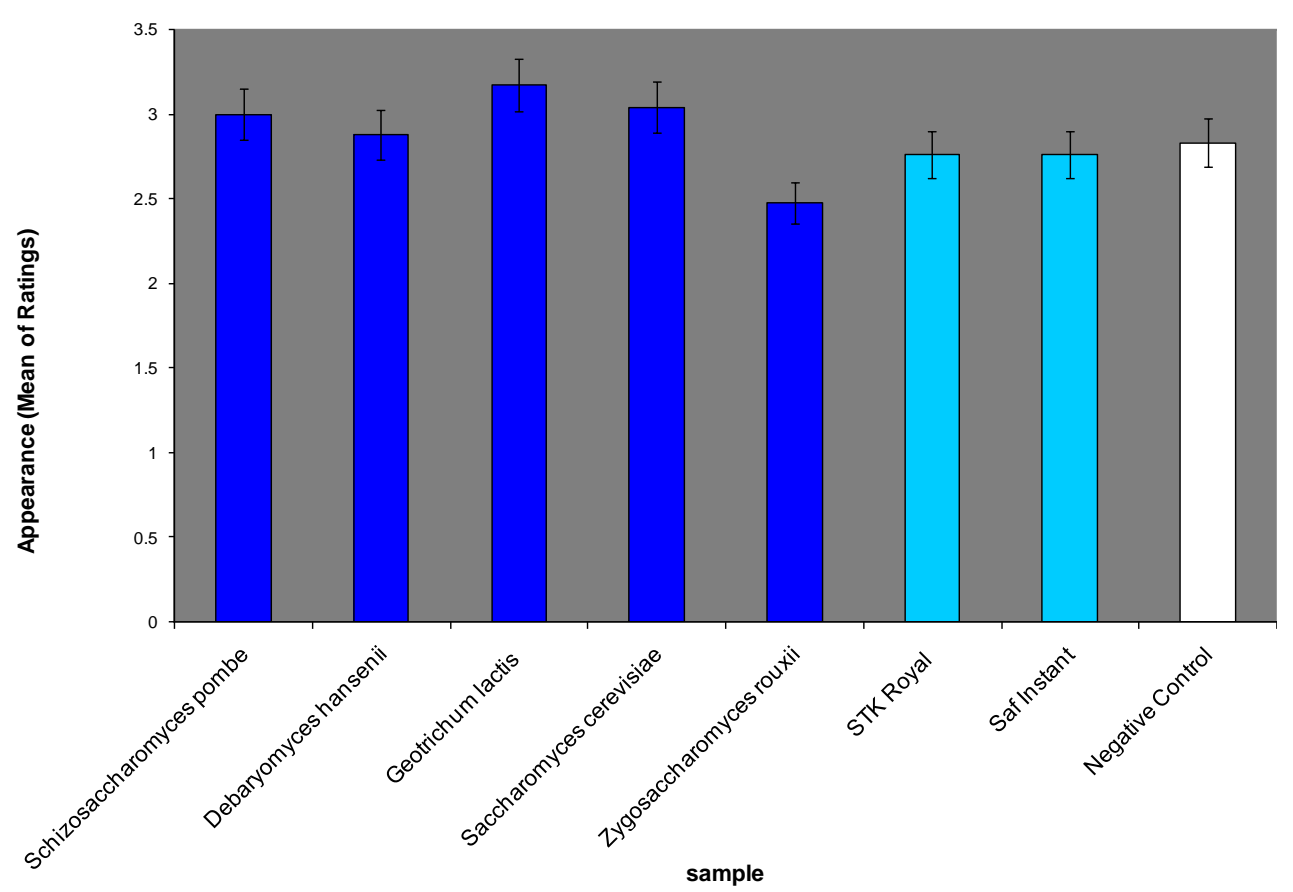

Fig. (5). Appearance of baked doughs made with the various yeasts isolated frompalm wine.

positive control did not differ significantly from the negative control. This means that the appearance and tastes of fermented doughs after baking may not be totally dependent on yeast activity, rather on the ingredient formulation as all the dough samples contained the ingredients in equal proportion. Hence, the iso-lated yeasts produced doughs with acceptable sensory attributes of taste and appearance with no significant difference from the commercially available yeasts.

In conclusion, this work has shown that palm wine contains yeasts that can produce baked doughs with good sensory attributes that compares favourably with commercial yeasts used for baking. The yeasts isolated from palm wine have shown considerable leavening activity.

\section{ACKNOWLEDGEMENT}

The authors are grateful to G.F. Hassan in the Department of Crop, Soil and Pest Management of the University for his assistance to use relevant facilities and provision of some materials for this work. Akharaiyi, F. C. ensured that the bench work of this project was successful.

\section{REFERENCES}

[1] Okagbue RN. A note on the leavening activity of yeasts associated with palm wine. J Appl Bacteriol 1988; 64: 235-40.

[2] Ogbulie TE, Ogbulie JN, Njoku HO. Comparative study on the shelf life stability of palm wine from Elaeis guineensis and Raphia hookeri obtained from okigwe, Nigeria. Afr J Biotechnol 2007; 6(7): 914-22.
[3] Obire O. Activity of yeast species in palm sap obtained from three areas in Edo state, Nigeria. J Appl Sci Environ Manage 2005; 9: 25-30.

[4] Ezenronye OU, Okerentugba PO. Genetic and physiological variant of yeasts selected from palm wine. Mycopathologia 2001; 15(2): 85-9.

[5] Frazier WC, Westhoff DC. Food Microbiology. $4^{\text {th }}$ ed. New Delhi: Tata McGraw-Hill publishing Company Limited 1995; pp. 384-96.

[6] Harrigan WF. Laboratory methods in food microbiology. $3^{\text {rd }}$ ed. San Diego Carlifornia: Academic Press 1998; pp. 36-84.

[7] Olutiola PO, Famurewa O, Sontag HG. An introduction to general microbiology: a practical approach. $1^{\text {st }}$ ed. Published by Heideberger Verlagsanstalt and Druckerei GmbH: Heldelberg 1991; pp. 424.

[8] Barnett JA, Payne RW, Yarrow D. Yeast characteristics and identification. London: Cambridge University Press 2000; pp. 100-21.

[9] Fawole MO, Oso BA. Laboratory manual in microbiology. $3^{\text {rd }}$ ed. 2001; pp. 102-50.

[10] Cauvian SP, Young L. Technology of bread making. London: Blackie Academy and Professional 1998; pp. 210-35.

[11] Phaff HJ. Isolation of biotechnological important organisms from nature. $2^{\text {nd }}$ ed. New York: Oxford Press 1990; pp. 384-5.

[12] Somiari RI, Udoh AE. Evaluation of the performance of yeasts isolated from sap of Elaeis guineensis in dough leavening. J Food Niger 1993; 1: 34-44.

[13] Adenaike O, Ameh JB, Whong CMZ. Comparative studies of the fermentative capacity of baker's yeast and local yeast strains (Saccharomyces species) isolated from fermented beverages. Book of Abstracts for the Annual Conference of Nigerian Mycological Society 2006; pp. 18-9.

[14] Olorunfemi OB, Adetuyi FA. Isolation of baking yeasts from naturally fermented pineapple. J Food Agric Environ 2005; 3 (1): 1157.

[15] Corriher S. Yeast crucial role in bread making. Fine Cooking 2001; 43: 80-1. 